\title{
Comparative study on corrosion resistance and lubrication function of lithium complex grease and polyurea grease
}

\author{
Guanlin REN ${ }^{1}$, Pengfei ZHANG ${ }^{1}$, Xiangyuan $\mathrm{YE}^{2}$, Wen $\mathrm{LI}^{1}$, Xiaoqiang FAN ${ }^{3,}$, Minhao $\mathrm{ZHU}^{1,3}$ \\ ${ }^{1}$ Tribology Research Institute, School of Mechanical Engineering, Southwest Jiaotong University, Chengdu 610031, China \\ ${ }^{2}$ Shaanxi Key Laboratory of Phytochemistry, College of Chemistry \& Chemical Engineering, Baoji University of Arts and Sciences, Baoji \\ 721013, China \\ ${ }^{3}$ Key Laboratory of Advanced Technologies of Materials (Ministry of Education), School of Materials Science and Engineering, Southwest \\ Jiaotong University, Chengdu 610031, China
}

Received: 02 July 2019 / Revised: 06 August 2019 / Accepted: 03 September 2019

(C) The author(s) 2019.

\begin{abstract}
In this study, lithium complex grease (LCG) and polyurea grease (PUG) were synthesized using mineral oil (500SN) and polyalphaolefin (PAO40) as base oil, adsorbed onto lithium complex soap and polyurea as thickeners, respectively. The effects of grease formulation (thickener and base oil with different amounts (80, 85, and $90 \mathrm{wt} \%$ ) on the corrosion resistance and lubrication function were investigated in detail. The results have verified that the as-prepared greases have good anti-corrosion ability, ascribed to good salt-spray resistance and sealing function. Furthermore, the increase in the amount of base oil reduces the friction of the contact interface to some extent, whereas the wear resistance of these greases is not consistent with the friction reduction, because the thickener has a significant influence on the tribological property of greases, especially load-carrying capacity. PUG displays better physicochemical performance and lubrication function than LCG under the same conditions, mainly depending on the component/structure of polyurea thickener. The polyurea grease with $90 \mathrm{wt} \%$ PAO displays the best wear resistance owing to the synergistic lubrication of grease-film and tribochemical film, composed of $\mathrm{Fe}_{2} \mathrm{O}_{3}, \mathrm{FeO}(\mathrm{OH})$, and nitrogen oxide.
\end{abstract}

Keywords: lithium complex grease; polyurea grease; salt-spray resistance; tribological property

\section{Introduction}

In recent years, increasing attention has been paid to offshore engineering equipments, because their operating conditions remain hot and humid air, seawater splashing, and salt-spray corrosion, causing serious corrosion and wear to metal components [1-3]. These causes of damage are the main threats to the performance and service life of marine engineering equipments [4]. Salt-spray corrosion causes serious damage, even failure, to mechanical parts in the ocean atmosphere [5, 6]. Therefore, it is of great significance to take effective protection to ensure the reliability and security of offshore engineering equipments.
Lubricating grease could serve as corrosion resistant material owing to its inherent sealing function [7]. The higher consistency differed from liquid lubricant, preventing contaminants from entering the contact surface, possibly displaying good corrosion protection [8]. Nevertheless, the corrosion resistance of grease has been rarely investigated up to now. Therefore, it is imperative to exploit the salt-spray resistance of grease.

As a semi-solid colloidal dispersion system, lubricating grease has been widely applied to many fields owing to its excellent friction-reducing and anti-wear properties. Grease contains two main components: base oil as a fluid lubricant and thickener for thickening the base oil to a certain consistency [9]. The properties

* Corresponding author: Xiaoqiang FAN, E-mail: fxq@home.swjtu.edu.cn 
of base oil and thickener mainly determine the physicochemical property and usability of grease. The previous study suggested that the solvency of the base oil strongly impacts the pumpability and rheological properties of grease, and is in a close relation with the thickener [10]. The base oil could bleed from the thickener; then, the grease softens under compression and shearing [11]. The type of base oil, structure of thickener, and their interaction strongly determine the operating conditions (load-bearing ability, running speed) and environment (e.g., high/low temperature, humid, dust) [12]. Meanwhile, the lubricating function of grease strongly depends on the base oil and thickener. It has been ensured that the thickener could deposit on the worn surface during the friction process and form a boundary protective film [13]. For greases with the same formulation, higher thickener concentration and higher viscosity of base oil can form a thicker film [14], which is closely correlated to the anti-wear and extreme pressure performance. The base oil, thickener, and their concentration play an important role in the performance of lubricating grease. However, only a few reports have methodically pointed out the effect of grease components.

Generally, lubricating grease can be divided into two categories: soap grease and non-soap grease [15]. Lithium complex grease and polyurea grease as the most prominent representatives of soap-base grease and non-soap base grease, respectively, have been applied in many fields. The ever-increasing production of the two greases accounts for more than half of the high-performance grease market. Lithium complex grease (LCG), as a type of high-performance soap grease, assumes the major share of the worldwide industrial grease market. It differs from traditional soap-based grease because of the thickener with diverse lithium soaps [16]. Lithium complex soap is prepared by the saponification reaction of stearic acid and organic acid with $\mathrm{LiOH}$ [17]. The development of LCG began in the 1960s, because of its higher dropping point. It has quickly replaced many traditional greases, such as calcium-based grease and sodium-based grease in various fields. In recent years, the relationship between the components and properties of LCG has been a popular research topic. A previous study reported that formulated LCG has excellent rheology and anti-wear properties via the saponification reaction $(12-\mathrm{OH}$ stearic acid, nonanedioic acid, and lithium hydroxide) [18]. Antioxidant additives with different chemical structures were selected to improve the oxidation stability of LCG [19]. ZDDP and MoDTC as LCG additives could strongly enhance anti-wear performances [20]. In the development of LCG thus far, it has possessed the advantages of high dropping point, wide temperature range, excellent colloidal stability, shear stability, and long service life [21]. Polyurea grease (PUG), as a type of non-soap grease, has become a new multipurpose grease after complex soap grease and bentonite grease [22]. Since its invention in 1954, PUG has been the subject of many research efforts, owing to its excellent performance characteristics. As of 2013, the total production of polyurea grease was $66.1 \mathrm{kt}$, accounting for $5.62 \%$ of the global grease production. Its thickener from reacting organic amine with isocyanate avoided the oxidation of metallic soap to base oils [23]. The long working life over a wide temperature range is mainly ascribed to the oxidation stability of the thickener. PUG has a series of excellent comprehensive properties, such as high dropping point, oxidation stability, thermal and mechanical shearing stability, rust resistance, and water resistance [24]. Ref. [25] has investigated the relationship between the PUG formulation and performance, and the tribological performance via adding ionic liquid. The rheology and anti-wear properties of PUG were also investigated via using sebacic acid ester and esters of polyols as a base oil [26]. The effect of thickener structure on the performance of PUG was also evaluated [27]. Above all, although a large amount of literature reported the relationship between performance characteristics and ingredients/ structure of the two greases, the salt-spray resistance of grease has never been investigated thus far [28].

Here, the effects of base oil, thickener, and their concentrations on the performance characteristics of grease were investigated, especially corrosion resistance. Lithium complex soap and polyurea were used to thicken two types of base oil, with the different concentrations of 20,15 , and $10 \mathrm{wt} \%$. The selected base oils were mineral oil (500SN, MO) and PAO40 (poly- $\alpha$-olefin, PAO). The physicochemical properties, salt-spray resistance, and tribological performance of the as-prepared greases were evaluated in detail. The 
friction mechanism was analyzed by surface/interface technology.

\section{Experimental details}

\subsection{Materials}

Sebacic acid, 12-OH stearic acid, $\mathrm{LiOH}$, diphenylmethane diisocyanate, octadecylamine, octadecyl alcohol, and ethanol and petroleum ether used in this study were purchased from Kelong Chemical Reagent Company. Base oil (500SN, PAO40) was commercially obtained from Lanzhou Refinery Company (Lanzhou, China). All chemicals in this work were employed without further purification.

\subsection{Preparation of salt-spray resistant greases}

\subsubsection{Lithium complex grease}

First, $60 \mathrm{wt} \%$ base oil was heated to $80^{\circ} \mathrm{C}$, following the complete dissolution of $12-\mathrm{OH}$ stearic acid in base oil under uniform stirring. Then, the temperature of the mixture was raised to approximately $125^{\circ} \mathrm{C}$, and sebacic acid was added into the mixture. After forming the homogeneous solution, the temperature was decreased to $100{ }^{\circ} \mathrm{C}$, and heat was preserved. Second, $\mathrm{LiOH}$ was dissolved in warm water (water is more than 3 times of the $\mathrm{LiOH}$ mass), and the $\mathrm{LiOH}$ aqueous solution was slowly added to the solution for approximately a half-hour. After the saponification at $115^{\circ} \mathrm{C}$ for $1 \mathrm{~h}$, the rest of the base oil was added. The blend was heated to $205^{\circ} \mathrm{C}$ and kept warm for $10 \mathrm{~min}$, then cooled to $180{ }^{\circ} \mathrm{C}$ for a half-hour. Finally, the initial grease was naturally cooled to $15-25{ }^{\circ} \mathrm{C}$, after being grounded/ homogenized on a three-roll mill three times, and high-end LCG was obtained. In this experiment, the base oils are $\mathrm{MO}$ and $\mathrm{PAO}$, and the thickener concentrations are 80, 85, and $90 \mathrm{wt} \%$; thus, six LCGs were obtained.

\subsubsection{Polyurea grease}

First, the base oil was heated to $120{ }^{\circ} \mathrm{C}$ and kept warm for 5-10 $\mathrm{min}$ to remove moisture. Second, 50 and $30 \mathrm{wt} \%$ base oils were offloaded into two beakers and kept warm with vigorous stirring; then, diphenylmethane diisocyanate (MDI) and octadecylamine were completely dissolved into them, respectively. Third, the mixture with octadecylamine was blended quickly into the $50 \mathrm{wt} \%$ mixture with MDI under constant stirring. Fourth, the remaining mixture in the beaker was cleaned with the remaining base oil, with the reaction temperature maintained between 105 and $125{ }^{\circ} \mathrm{C}$ for $60 \mathrm{~min}$. Finally, stearyl alcohol was added into the stirred vessel and reacted for 10-15 min. The temperature was heated to $170-180{ }^{\circ} \mathrm{C}$ for $20 \mathrm{~min}$ for high-temperature refining. The initial grease was naturally cooled to $\sim 25^{\circ} \mathrm{C}$, after being grounded/homogenized on a three-roll mill three times, the high-end PUG was obtained. In this experiment, the base oils are $\mathrm{MO}$ and $\mathrm{PAO}$, and their viscosities are listed in Table 1. The thickener concentrations are 80,85 , and $90 \mathrm{wt} \%$; thus, six PUGs were generated. Figure 1 shows the photos of as-prepared LCG and PUG.

\subsection{Physicochemical properties of as-prepared greases}

The dropping points of as-prepared greases were measured by the SYD-3498-I drop point tester (Shanghai JingXi Instrument Manufacturing Co., Ltd.) following

Table 1 Viscosity of MO (500SN) and PAO (PAO40).

\begin{tabular}{cccc}
\hline Project & \multicolumn{2}{c}{ Kinematic viscosity $\left(\mathrm{mm}^{2} / \mathrm{s}\right)$} & \multirow{2}{*}{$\begin{array}{c}\text { Viscosity } \\
\text { index }\end{array}$} \\
\cline { 2 - 3 } & $40{ }^{\circ} \mathrm{C}$ & $100{ }^{\circ} \mathrm{C}$ & 88 \\
\hline MO (500SN) & 97 & 11 & 154 \\
\hline
\end{tabular}
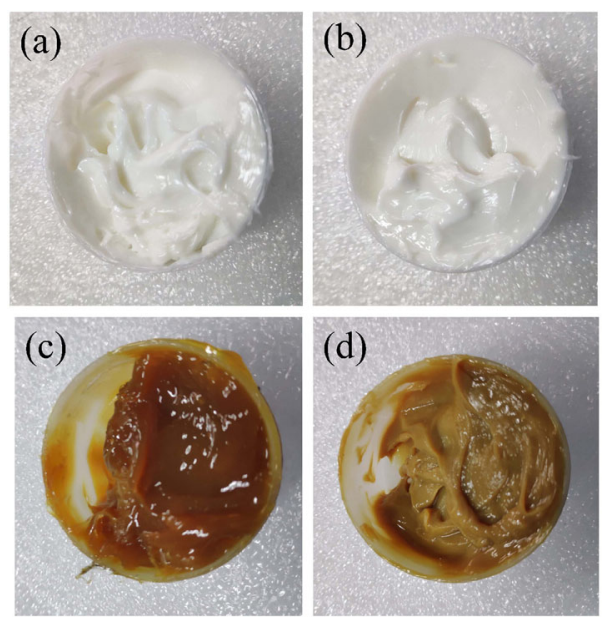

Fig. 1 Representative photos of as-prepared LCG and PUG: (a) LCG (85\% PAO), (b) PUG (85\% PAO), (c) LCG (85\% MO), and (d) PUG (85\% MO). 
ASTM-D566. The cone penetrations of the salt-spray resistant grease were measured by SYD-2801C lubricating grease cone penetrometer (Shanghai Changji Geological Instrument Co., Ltd.) according to GB/T 269 (ASTM D1403). The copper strip test was evaluated by national standards GB/T 7326-87 (ASTM D4048-81). The colloidal stability was tested by the National Petrochemical Industry standards SH/T 0324-92. Thermogravimetric analysis was performed in depth by NETZSCH SAT 449 F3 (NETZSCH Instrument Manufacturing Co., Ltd.), and the functional groups were analyzed by Fourier transform infrared analysis (FTIR, Nicolet-5700).

\subsection{Salt-spray test}

Salt-spray test is an accelerated corrosion method via simulating an ocean atmosphere [29]. The salt solution is sprayed into an airtight case at constant temperature, which atomizes a certain concentration of salt water. The salt concentrations are several or dozens of times higher than their natural concentrations. Therefore, the corrosion rate is greatly accelerated, and the corrosion time is considerably shortened. The saltspray resistance was evaluated by observing the changes in the specimens before and after the test. LCG, containing $85 \mathrm{wt} \% \mathrm{MO}$ and PAO (LCG $(85 \%$ $\mathrm{MO})$ and LCG (85 wt $\%$ PAO)), and PUG, containing $85 \mathrm{wt} \% \mathrm{MO}$ and $85 \%$ PAO (PUG (85 wt\% MO) and PUG (85 wt $\%$ PAO)), were sorted out to investigate the salt-spray resistance. The tested titanium alloy sheets were polished before coating the grease. The neutral salt-spray test was employed in this experiment following GB/T 1771-2007. The temperature in the salt-spray test chamber is $35{ }^{\circ} \mathrm{C}$, and the concentration of $\mathrm{NaCl}$ solution is $5 \%$. Each grease was daubed uniformly on the surfaces of titanium alloy sheet and blank titanium alloy sheet as a reference. All the specimens are hung in the salt-spray test box with a rope. The salt-spray test was performed for two weeks, and the corrosion phenomenon was observed at intervals. After the salt-spray test, the grease was slightly scraped off the surface of titanium alloy with a scraper and ultrasonically cleaned in alcohol several times until cleaned completely. To evaluate the corrosion degree of the titanium alloy sheet, the changes in surface morphology were observed by scanning electron microscopy (SEM), using the JMS-6610 (SEM, JEOL, Japan), and the elemental composition and chemical state of the surface of titanium alloy were analyzed by Thermo Scientific ESCALAB 250Xi X-ray photoelectron spectroscopy (XPS). Considering that titanium alloy exhibits low-temperature performance, high chemical activity, thermal conductivity, and small modulus of elasticity, titanium alloy was applied to explore the corrosion resistance of grease. In this case, the protection effect of grease can be highlighted. The coated grease on the titanium alloy sheet plays a sealing function role and prevents corrosive media from entering.

\subsection{Tribological properties of as-prepared greases}

The tribological performance of as-prepared greases was evaluated via UMT-3 reciprocating friction and wear tribometer (Center For Tribology Company, America) with the applied loads of $20 \mathrm{~N}$ (Hertzian contact pressure (HCP): $1.20 \mathrm{GPa}), 40 \mathrm{~N}$ (HCP: 1.59 $\mathrm{GPa}$ ), and $60 \mathrm{~N}$ (HCP: $1.82 \mathrm{GPa}$ ) at $\sim 25^{\circ} \mathrm{C}$ for $1 \mathrm{~h}$. The UMT-3 reciprocating friction and wear tribometer was designed with ball-on-disk contact configuration. The fixed upper specimen is made up of an AISI 52100 steel ball with a diameter of $10 \mathrm{~mm}$ and hardness of $710 \mathrm{HV}$, whereas the stationary lower specimen is also composed of AISI 52100 steel disks with $\Phi 24 \mathrm{~mm} \times$ $7.9 \mathrm{~mm}$ and a hardness of approximately $630 \mathrm{HV}$. The friction coefficients were measured by the computer linked to the UMT-3 reciprocating friction and wear tribometer. All the friction tests under the same condition were repeatedly performed three times. The friction pairs were ultrasonically cleaned several times in acetone before characterization.

\subsection{Surface analysis}

To investigate the tribological mechanism lubricated by the as-prepared greases, the morphology of the worn surfaces was analyzed by SEM, and the chemical state of elements on the surfaces was analyzed by XPS. Before the test, the specimens were cleaned ultrasonically several times in baths of petroleum ether and dried with pure nitrogen.

\section{Results and discussion}

\subsection{Physicochemical properties}

Table 2 shows the physicochemical properties of the 
Table 2 Physicochemical properties of salt-spray resistant greases.

\begin{tabular}{|c|c|c|c|c|c|c|}
\hline \multicolumn{3}{|c|}{ Project } & Dropping point $\left({ }^{\circ} \mathrm{C}\right)$ & $\begin{array}{l}\text { Penetration } \\
(0.5 \mathrm{~mm})\end{array}$ & $\begin{array}{c}\text { Copper corrosion } \\
\left(100^{\circ} \mathrm{C}, 24 \mathrm{~h}\right)\end{array}$ & $\begin{array}{l}\text { Oil separation } \\
\quad(\mathrm{w} / \mathrm{w} \%)\end{array}$ \\
\hline \multicolumn{3}{|c|}{ National standard } & ASTM-D566 & ASTM-D217 & ASTM-D4048-81 & $\mathrm{SH} / \mathrm{T}$ 0324-92 \\
\hline \multirow{6}{*}{ LCG } & \multirow{3}{*}{ MO } & $80 \mathrm{wt} \%$ & 315.33 & 21.03 & $1 \mathrm{a}$ & 1.65 \\
\hline & & $85 \mathrm{wt} \%$ & 302.00 & 23.40 & $1 \mathrm{a}$ & 1.87 \\
\hline & & $90 \mathrm{wt} \%$ & 234.33 & 28.64 & $1 \mathrm{a}$ & 3.09 \\
\hline & \multirow{3}{*}{ PAO } & $80 \mathrm{wt} \%$ & 314.67 & 15.49 & $1 \mathrm{a}$ & 1.06 \\
\hline & & $85 \mathrm{wt} \%$ & 307.33 & 34.33 & $1 \mathrm{a}$ & 1.32 \\
\hline & & $90 \mathrm{wt} \%$ & 256.67 & 44.59 & $1 \mathrm{a}$ & 2.00 \\
\hline \multirow{6}{*}{ PUG } & \multirow{3}{*}{ MO } & $80 \mathrm{wt} \%$ & 303.00 & 22.16 & $1 \mathrm{a}$ & 1.51 \\
\hline & & $85 \mathrm{wt} \%$ & 218.33 & 25.51 & $1 \mathrm{a}$ & 7.59 \\
\hline & & $90 \mathrm{wt} \%$ & 331.33 & 29.12 & $1 \mathrm{a}$ & 12.61 \\
\hline & \multirow{3}{*}{ PAO } & $80 \mathrm{wt} \%$ & 345.00 & 15.24 & $1 \mathrm{a}$ & 4.95 \\
\hline & & $85 \mathrm{wt} \%$ & 336.00 & 33.77 & $1 \mathrm{a}$ & 3.80 \\
\hline & & $90 \mathrm{wt} \%$ & 259.67 & 42.64 & 1a & 3.68 \\
\hline
\end{tabular}

as-prepared salt-spray resistant greases. It can be found that the dropping point of LCG was reduced as the concentration of thickener decreases, whereas the penetration of LCG shows the opposite trend. The LCG (80 $\mathrm{wt} \% \mathrm{MO})$ has the highest dropping point, reaching $315.3{ }^{\circ} \mathrm{C}$, followed by LCG ( $80 \mathrm{wt} \%$ PAO) and LCG (85 wt $\%$ PAO). The majority of the dropping points of the as-prepared salt-spray greases are above $300{ }^{\circ} \mathrm{C}$, indicating that the thermal stability of the as-prepared greases is outstanding. The penetration of the as-prepared greases increases as the concentration of the thickener decreases, suggesting that the thickening capacity is improved by the increase in the thickener concentration. The oil separation of LCG was no greater than $5 \%$, indicating good colloidal stability of LCG. The oil separation of PUG (85 $\mathrm{wt} \% \mathrm{MO})$ and PUG (90 wt\% MO) is higher than that of the PUG prepared by PAO. The oil separation test of LCG illustrates that the colloidal stability was improved in the following sequence: LCG $(90 \mathrm{wt} \% \mathrm{MO})>\mathrm{LCG}$ $(90 \mathrm{wt} \%$ PAO) $>$ LCG $(85 \mathrm{wt} \% \mathrm{MO})>\mathrm{LCG}(80 \mathrm{wt} \%$ $\mathrm{MO})>\mathrm{LCG}(85 \mathrm{wt} \% \mathrm{PAO})>\mathrm{LCG}(80 \mathrm{wt} \% \mathrm{PAO})$, and the colloidal stability of PUG was improved in the following sequence: PUG (90 $\mathrm{wt} \% \mathrm{MO}$ ) > PUG $(85 \mathrm{wt} \% \mathrm{MO})>$ PUG $(80 \mathrm{wt} \% \mathrm{PAO})>$ PUG $(85 \mathrm{wt} \%$ PAO) $>$ PUG (90 wt $\%$ PAO) > PUG (80 wt $\%$ MO). Thus, lithium complex soap and polyurea display a better thickening effect to MO. The copper corrosion test shows that grease-coated copper strips have nearly no change compared with polished copper ones, whereas coating-free copper strips appear to exhibit severe oxidation corrosion. These greases allow degrees of copper corrosion to be located at $1 \mathrm{a}$, indicating the good corrosion resistance of the as-prepared greases.

Thermogravimetric analysis (TGA) and differential scanning calorimetry (DSC) curves of as-prepared greases $(85 \mathrm{wt} \%$ base oil) are shown in Fig. 2 . The temperature was increased gradually from ambient temperature to $600{ }^{\circ} \mathrm{C}$ at a heating rate of $10^{\circ} \mathrm{C} \cdot \mathrm{min}^{-1}$ in nitrogen. The thermal decomposition temperature of the greases synthesized by PAO is higher than the greases synthesized by MO. The decomposition of LCG (85 $\mathrm{wt} \%$ PAO) and PUG (85 $\mathrm{wt} \%$ PAO) appeared at approximately $380^{\circ} \mathrm{C}$, whereas the decomposition of the other greases appeared at $320^{\circ} \mathrm{C}$, indicating that the as-prepared greases have outstanding thermal stability.

The FTIR spectra of the as-prepared greases are shown in Fig. 3. The peak of the N-H bond for PUG is located at $1,560 \mathrm{~cm}^{-1}$, and the stretching vibration peak of $\mathrm{C}=\mathrm{O}$ bond appears at $1,630 \mathrm{~cm}^{-1}$, inferring the carbamido of polyurea thickener [30]. The stretching vibration peak of $\mathrm{C}=\mathrm{O}$ bond for LCG appears at $1,370 \mathrm{~cm}^{-1}$, which corresponds to the carboxylate- 

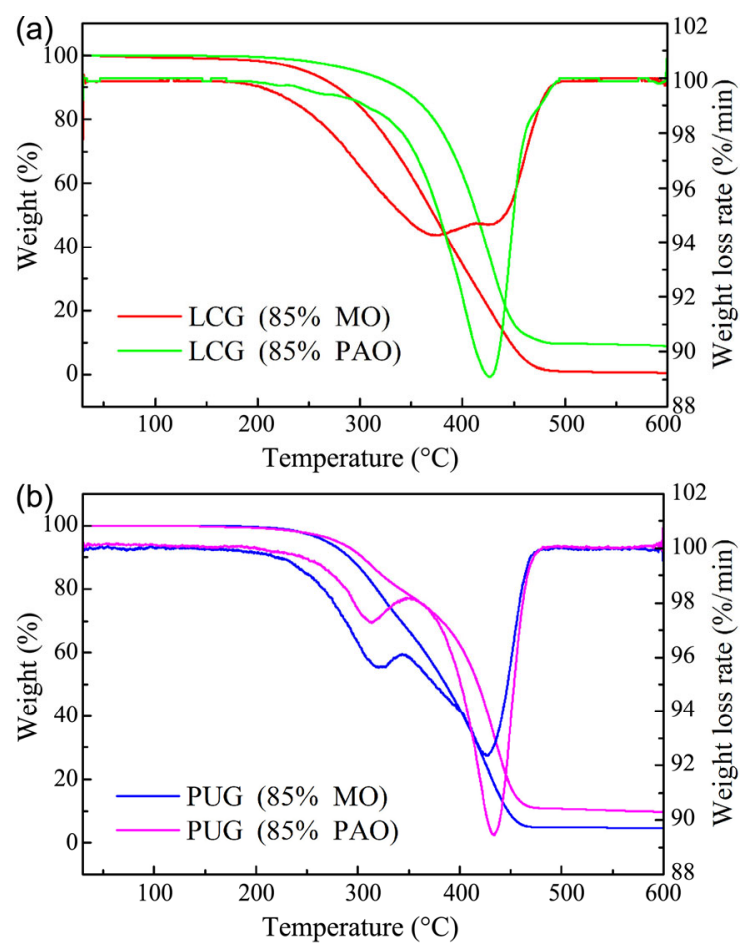

Fig. 2 Thermo-gravimetric analysis curves of as-prepared greases: (a) LCG and (b) PUG.
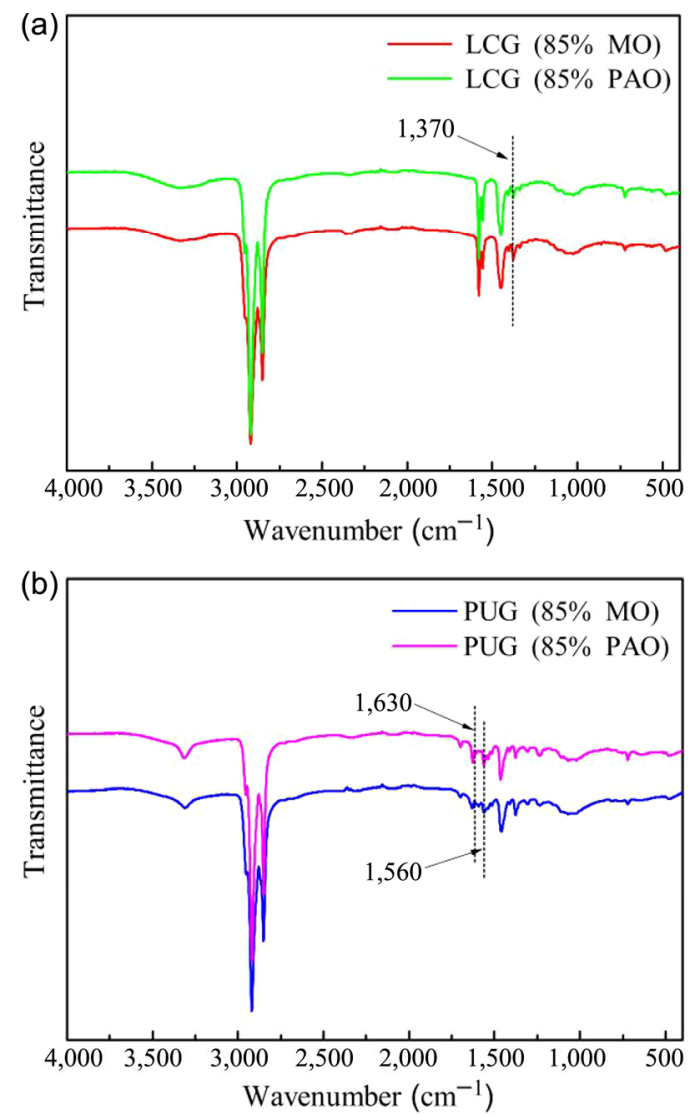

Fig. 3 Fourier transform infrared analysis spectra of as-prepared salt-spray resistant grease. containing groups from lithium complex soap [31]. The diversity of the physicochemical characteristics for the as-prepared greases could be attributed to the sensitivity of the base oil and thickener, chemical component, and structure of thickener.

\subsection{Surface analysis of salt-spray test}

SEM is an effective and universal tool for analyzing surface topography. Thus, SEM was employed to observe the morphology of titanium alloy coated by the greases after the salt-spray test. Figure 4 displays severe corrosion with an obvious rusty spot on the surface of the coating-free titanium alloy. In contrast, the surface of the grease-coated titanium alloy is nearly identical to that of the new polished titanium alloy. The grease protected the titanium alloy from the external environment owing to the sealing function; thus, it prevented the corrosive medium from reaching the titanium alloys. Thus, as-prepared greases can effectively prevent the metal from corrosive damage, which can prolong the service life of machinery equipment and reduce waste of resources.

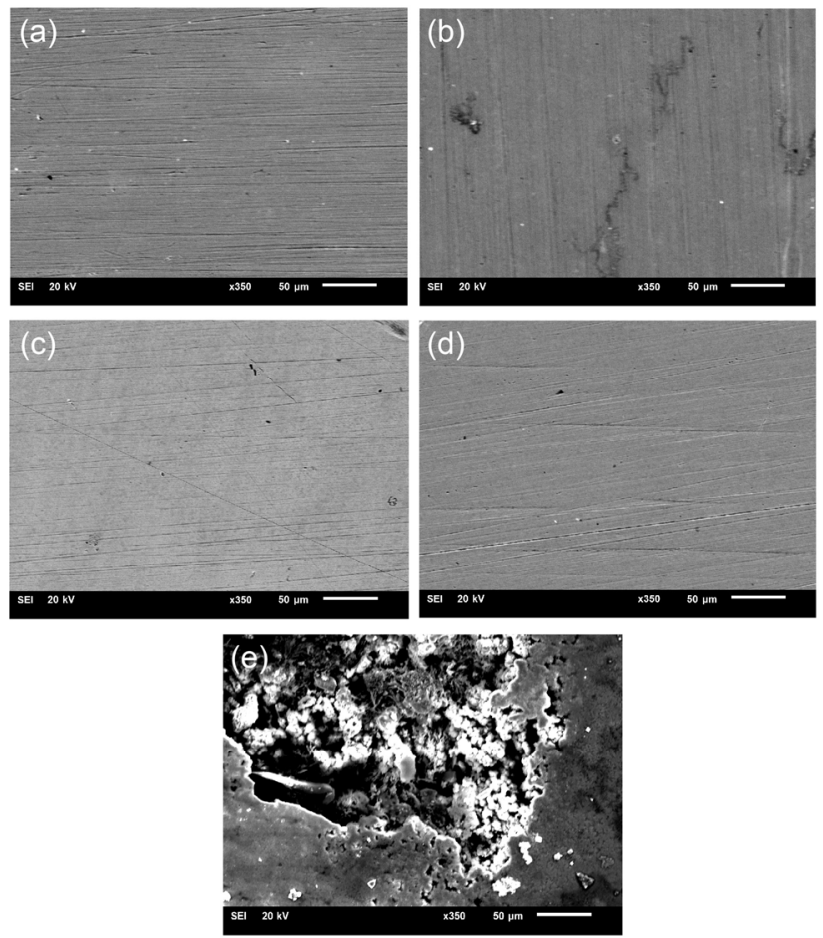

Fig. 4 SEM morphologies of the titanium alloy after the salt-spray tests: (a) LCG (85 wt\% MO), (b) LCG (85 wt\% PAO), (c) PUG (85 wt $\%$ MO), (d) PUG (85 wt $\%$ PAO), and (e) blank titanium alloy. 


\subsection{XPS analysis of salt-spray test}

XPS spectra of corrosion surfaces on titanium alloys are displayed in Fig. 5, with the peak of C1s at $284.8 \mathrm{eV}$ corresponding to $\mathrm{C}$ in the air. The peaks of O1s on the grease-coated surfaces at $532.3 \mathrm{eV}$ are attributed to the appearance of $\mathrm{TiO}_{2}$. The O1s peak on the coatingfree titanium alloy appears at $531.3 \mathrm{eV}$, which was inferred as the appearance of oxidative products, such as $\mathrm{Al}_{2} \mathrm{O}_{3}$ and $\mathrm{TiO}_{2}$. The $\mathrm{Cl} 2 \mathrm{p}$ peak on the coating-free titanium alloy is at $198.4 \mathrm{eV}$, whereas weaker peaks appear on the grease-coated surfaces, indicating the appearance of chloride (e.g., $\mathrm{LiCl}, \mathrm{NaCl}$, and $\mathrm{VCl}_{2}$ ) on the coating-free surface. In addition, the V2p peak of the coating-free surface is located at $531.2 \mathrm{eV}$, whereas the V2p peaks of the grease-coated surfaces appear at 530 and $532.1 \mathrm{eV}$, possibly ascribed to the appearance of $\mathrm{V}_{2} \mathrm{O}_{5}$. Although there was slight oxidation on the
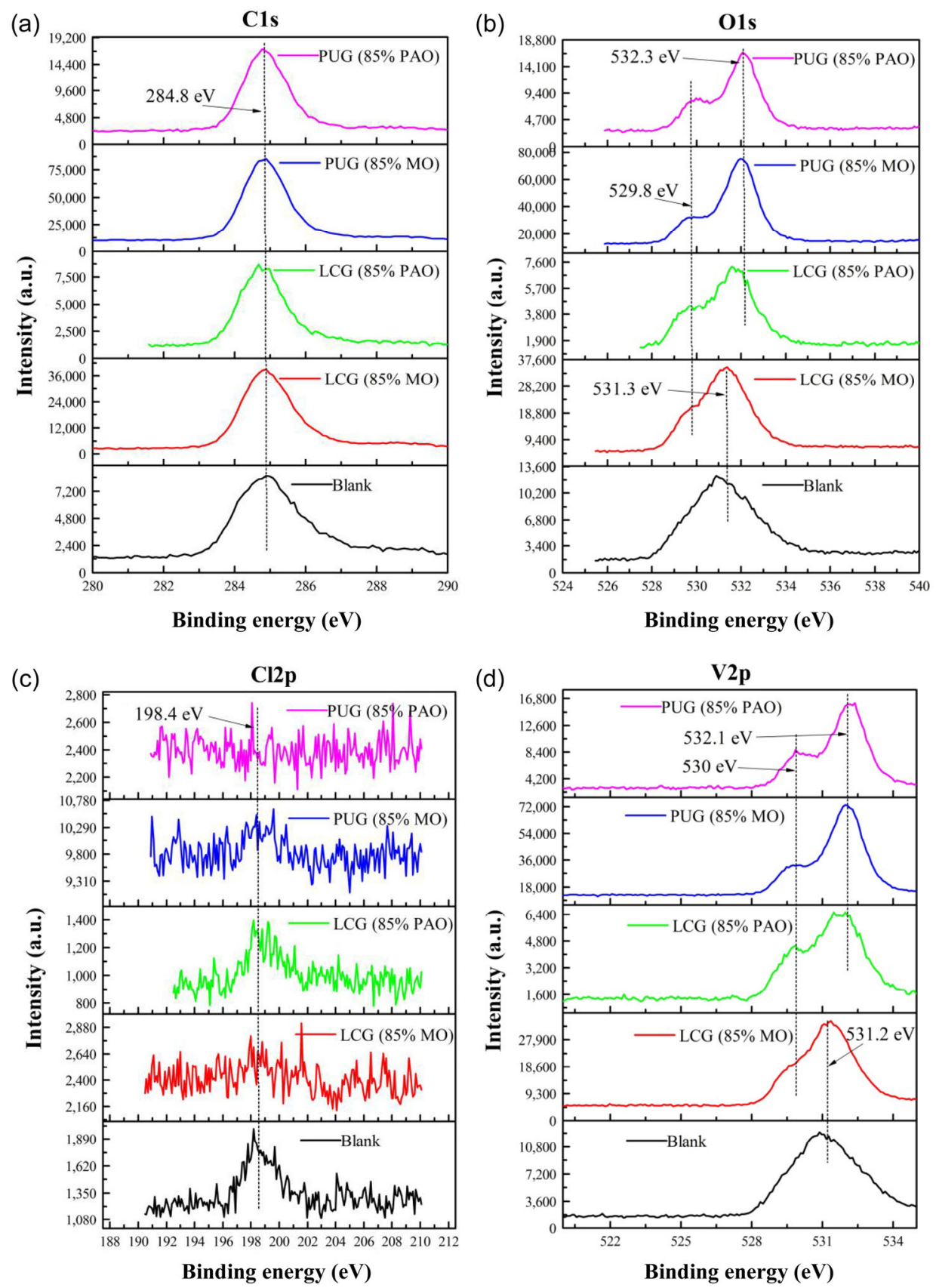

Fig. 5 X-ray photoelectron spectra of the elements on the surface of titanium alloys after salt-spray test. 

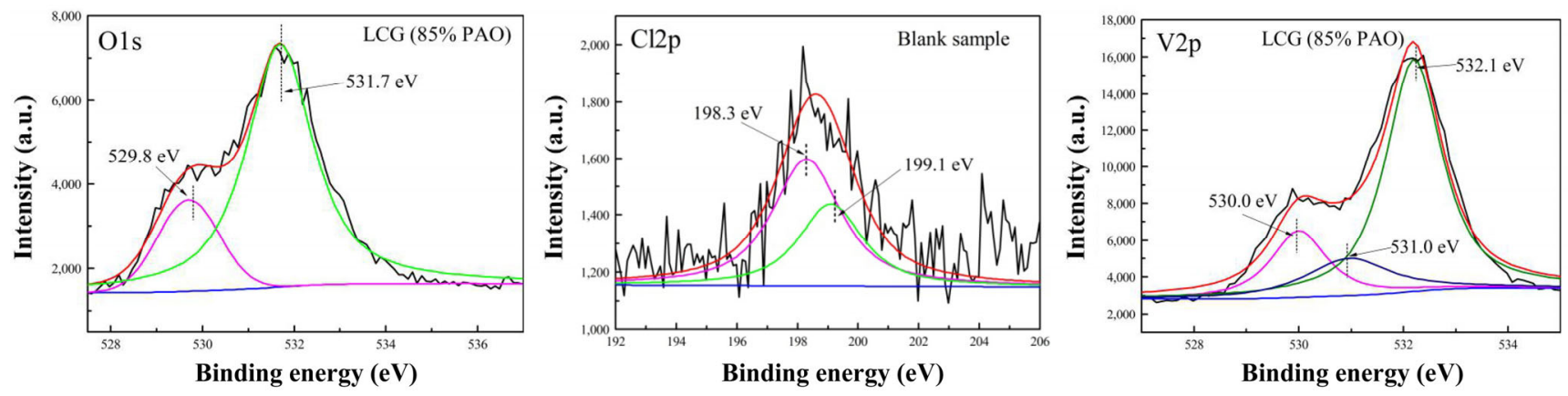

Fig. 5 (Continued)

surface of the grease-coated titanium alloy, few obvious examples of corrosion occurred on the worn surface compared with that of the coating-free surface. Consequently, it is concluded that the grease displays good corrosion protection effect, preventing the metal parts from corroding.

\subsection{Tribological properties}

The tribological properties of lubricating greases were evaluated on a reciprocating ball-on-disk UMT-3 sliding tester at $\sim 25{ }^{\circ} \mathrm{C}$. Figure 6 shows the friction curves and average friction coefficients of steel/steel contact
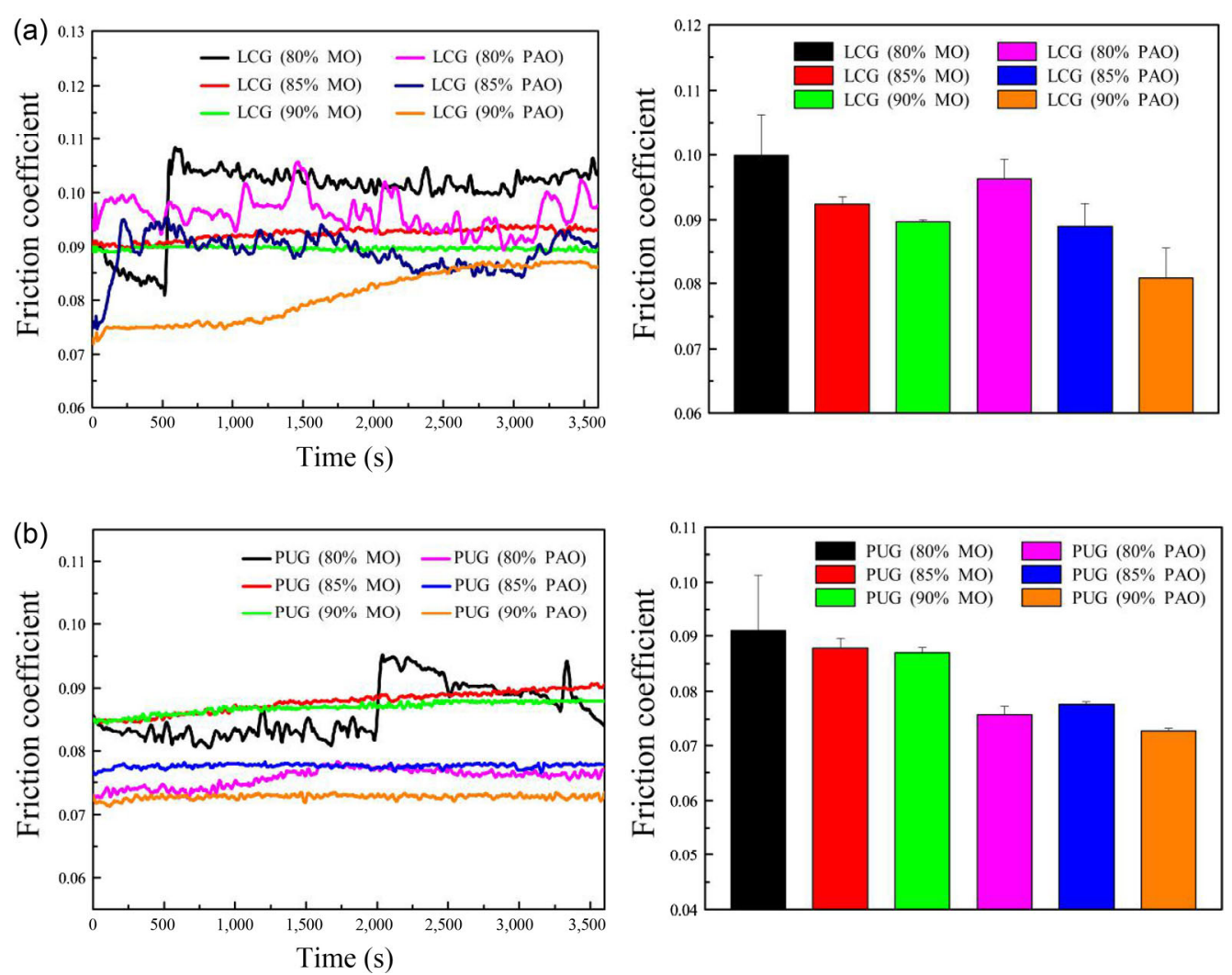

Fig. 6 Evolution of the friction coefficient with time under the applied load of (a, b) 20, (c, d) 40, and (e, f) $60 \mathrm{~N}$. under grease lubrication at 20,40, and $60 \mathrm{~N}$. Under the applied load of 20 and $40 \mathrm{~N}$, the friction curves lubricated by LCG (80 wt\% MO), LCG (80 wt\% PAO), and LCG ( $85 \mathrm{wt} \%$ PAO) fluctuate vigorously, showing a tendency of first increase then level off, possibly because the high consistency has an adverse effect on the liquidity of grease (highly-thickened grease is of replenishing base oil to form new lubricating film). The friction reduction of LCG decreases with thickener concentration, namely, the thinner consistency of grease is good for the formation of lubricating film. The LCG (except for LCG with $90 \mathrm{wt} \%$ PAO) provides roughly 

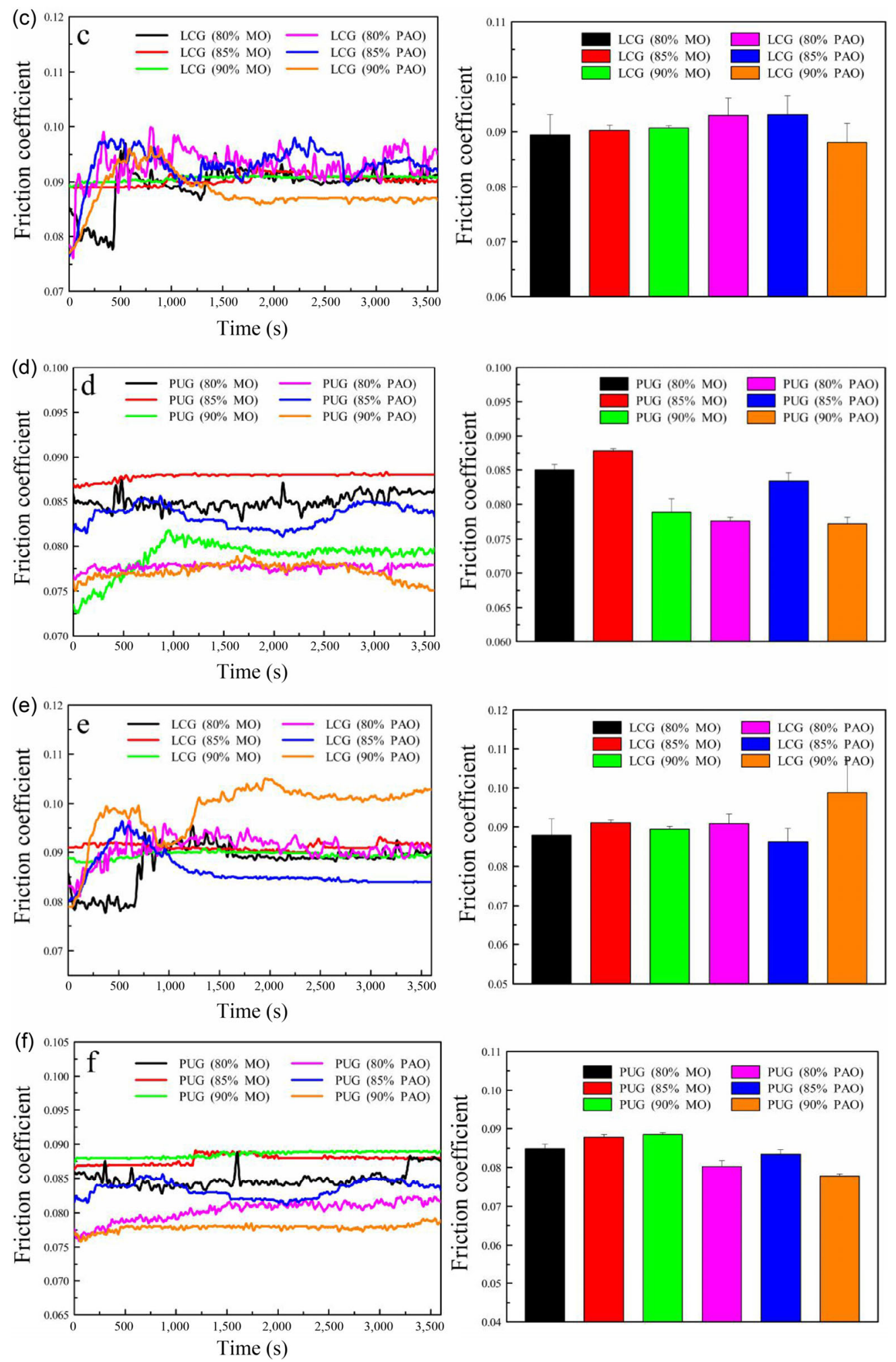

Fig. 6 (Continued)

uniform friction coefficients at the applied load of $60 \mathrm{~N}$, whereas the friction coefficient of PUG with PAO is lower than that of PUG with MO, indicating that PUG with PAO exhibits better friction-reducing ability. Above all, the LCG formulated by the same base oil gives low friction cofficients values with the decrease 
in the content of thickener, indicating that LCG with low thickener content provides better friction-reducing and anti-wear abilities. From what has been discussed above, the friction coefficients of the as-prepared grease are less than 0.1 , and the friction coefficient under LCG lubrication increases as follows: LCG (90 wt\% PAO) < LCG (85 wt\% PAO) < LCG (90 wt \% MO) < LCG $(85 \mathrm{wt} \% \mathrm{MO})<\mathrm{LCG}(80 \mathrm{wt} \% \mathrm{MO})<\mathrm{LCG}(80 \mathrm{wt} \%$ PAO). Under PUG lubrication, the friction coefficient increases as the following: PUG $(90 \mathrm{wt} \% \mathrm{PAO})<\mathrm{PUG}$ $(80 \mathrm{wt} \%$ PAO) < PUG $(85 \mathrm{wt} \%$ PAO) < PUG $(90 \mathrm{wt} \%$ $\mathrm{MO})<$ PUG $(80 \mathrm{wt} \% \mathrm{MO})<$ PUG $(85 \mathrm{wt} \% \mathrm{MO})$.

Figure 7 displays the wear volume of the lower specimen under as-prepared grease lubrication. Under the applied load of $20 \mathrm{~N}$, the grease containing $80 \mathrm{wt} \%$ base oil provides a higher wear volume than that of other greases, possibly owing to the poor bleeding oil ability of high-consistency grease, resulting from the starved conditions of grease lubrication. Under the applied load of $40 \mathrm{~N}$, the LCG containing $80 \mathrm{wt} \%$ and $85 \mathrm{wt} \%$ PAO shows higher wear volume than do others. All the greases with $90 \mathrm{wt} \%$ base oil appear to exhibit lower wear volume, indicating the excellent anti-wear ability of the as-prepared grease with highcontent base oil. The PUG exhibits a lower wear volume than does LCG. The LCG with $80 \mathrm{wt} \%$ and $90 \mathrm{wt} \%$ $\mathrm{PAO}$ at $60 \mathrm{~N}$ gives a higher wear volume as well, indicating that the LCG prepared by PAO possesses weaker anti-wear ability. As-prepared greases with $\mathrm{MO}$ possess superior wear resistance to those prepared by PAO as a comparison. The wear volumes lubricated by PUG are lower than those lubricated by LCG, indicating that the anti-wear property of PUG is superior to that of LCG, especially PUG containing $90 \mathrm{wt} \% \mathrm{MO}$ with the best anti-wear property. Thus, good interaction of polyurea and MO allows the as-prepared greases to have excellent physicochemical and tribological properties. The good interaction is mainly derived from the chemical composition and structure of the thickener, and its sensitivity to base oil.

\subsection{Morphology analysis of worn surface}

Figure 8 displays the SEM images and corresponding three-dimensional morphologies of wear tracks under LCG lubrication at the applied load of 40 N. From
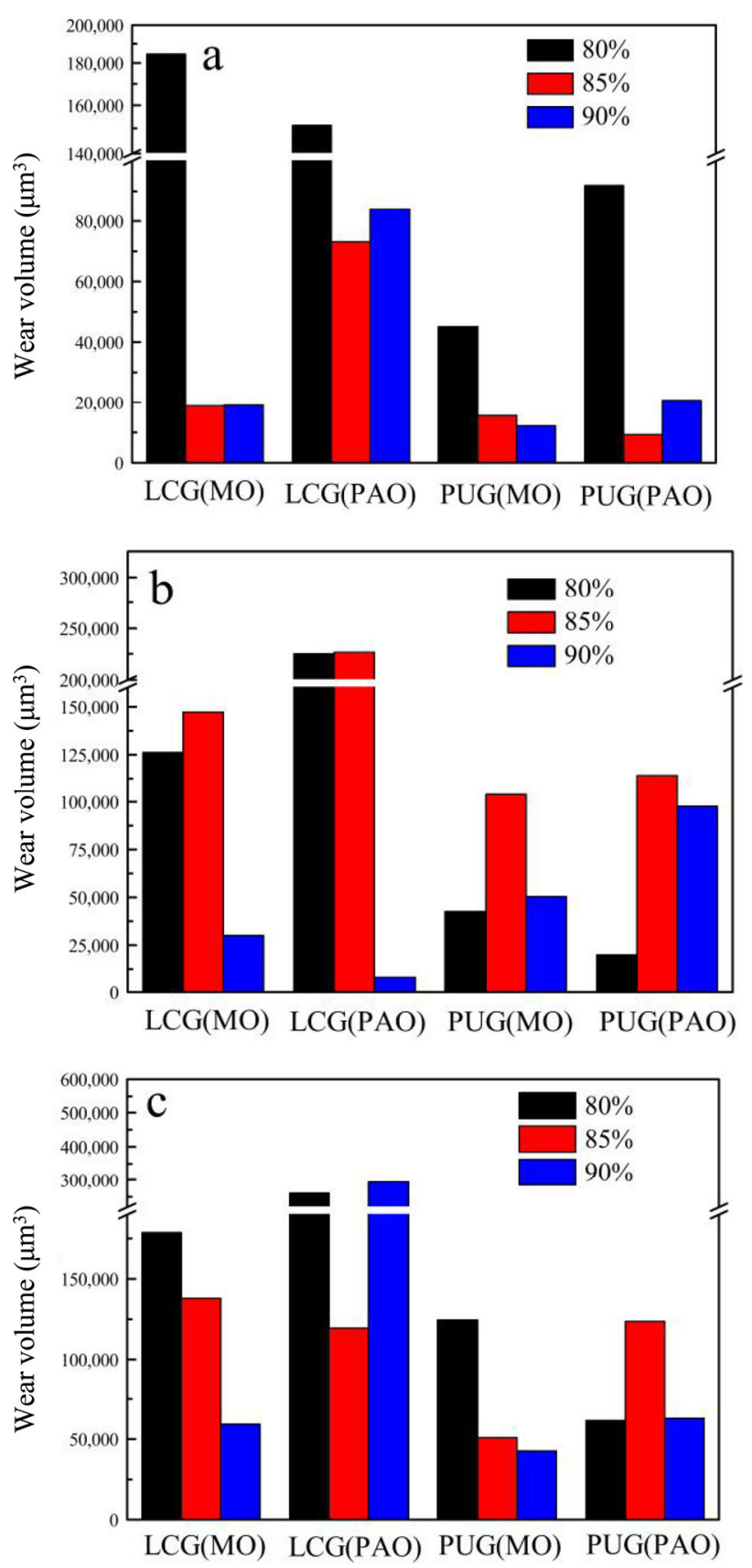

Fig. 7 Wear volumes of the lower specimen lubricated by the as-prepared salt-spray resistant greases: (a) $20 \mathrm{~N}$, (b) $40 \mathrm{~N}$, and (c) $60 \mathrm{~N}$.

Fig. 8, the rubbing surfaces lubricated by LCG with $80 \mathrm{wt} \%$ and $85 \mathrm{wt} \% \mathrm{MO}$ appear with some wide and deep furrows, whereas the LCG containing $90 \mathrm{wt} \%$ MO shows a flat and shallow wear scar. Meanwhile, the rubbing surface lubricated by PAO-based LCG appears to exhibit the same phenomenon, suggesting that the LCG with $90 \%$ base oil has a superior lubrication function to LCG with other concentrations 

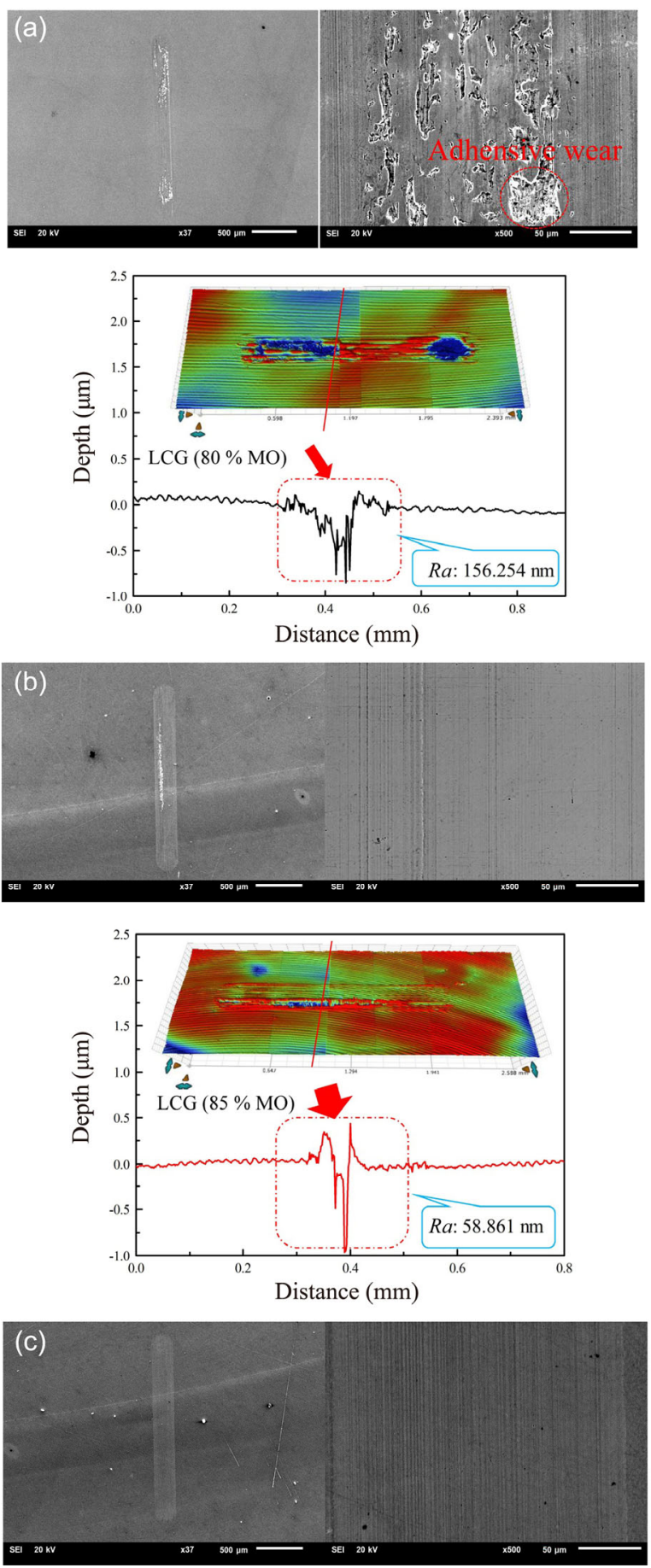
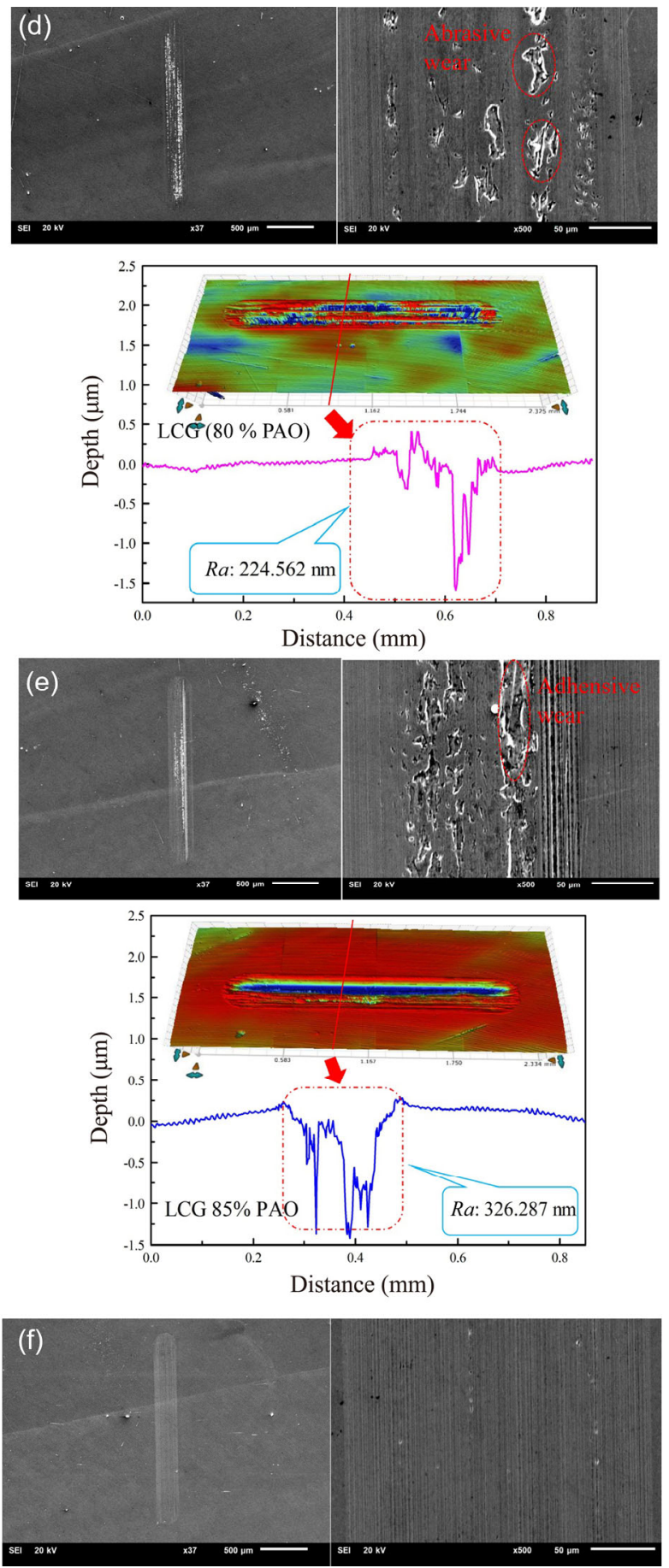

Fig. 8 SEM morphologies and particle of three-dimensional morphologies of the worn surfaces of lower specimen lubricated by LCG with the applied load of $40 \mathrm{~N}$. (a) LCG $80 \%$ MO, (b) LCG $85 \%$ MO, (c) LCG 90\% MO, (d) LCG 80\% PAO, (e) LCG $85 \%$ PAO, and (f) LCG 90\% PAO.

of base oil. In addition, the PAO-based LCG with concentrations of $80 \%$ and $85 \%$ appear to exhibit severe wear compared with the PUG with $80 \%$ and 85\% MO, indicating the MO-based PUG has a better lubrication function.
Compared with the LCG, Fig. 9 gives the surface morphologies under PUG lubrication at the applied load of $40 \mathrm{~N}$. The wear tracks lubricated by the PUG with all formulations show narrow and shallow wear tracks with shallow furrows, indicating that the PUG 

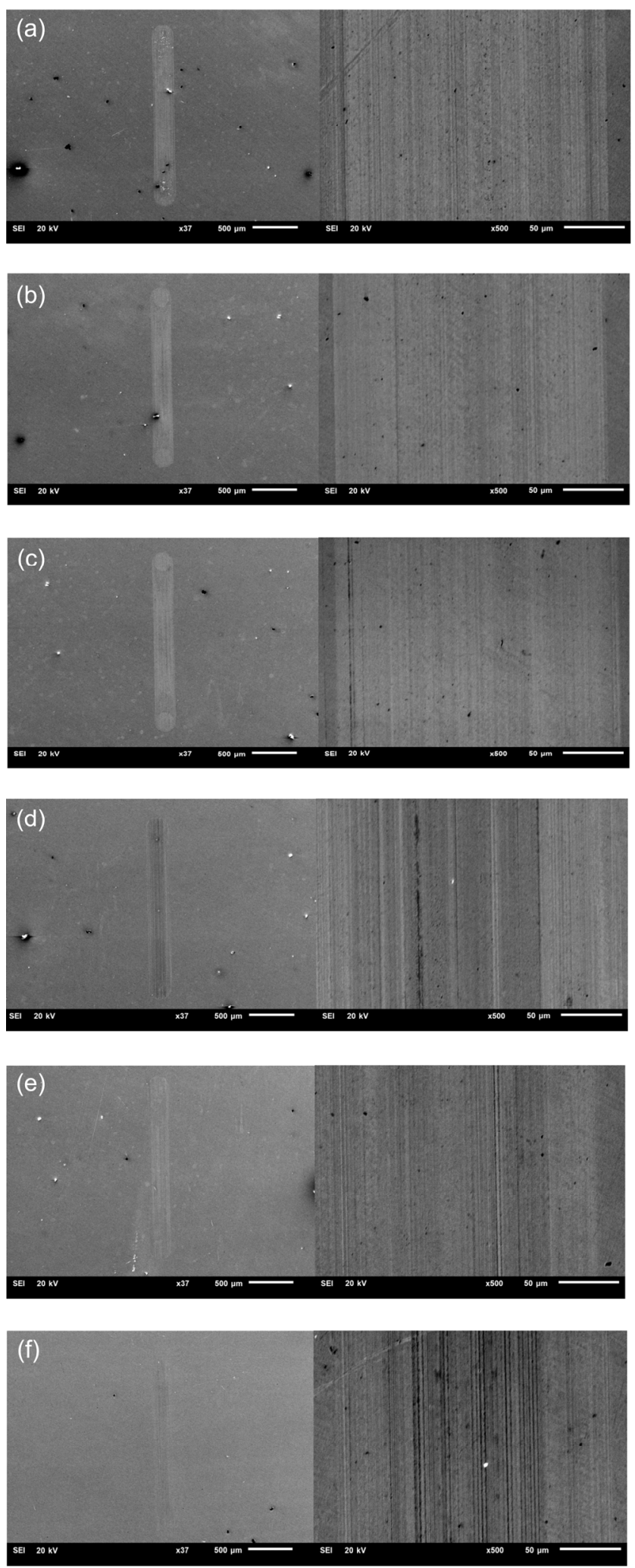

Fig. 9 SEM morphologies of the worn surfaces of the lower specimen lubricated by PUG with the applied load of 40 N. (a) PUG $80 \%$ MO, (b) PUG 85\% MO, (c) PUG 90\% MO, (d) PUG 80\% PAO, (e) PUG $85 \%$ PAO, and (f) PUG 90\% PAO. has better anti-wear ability than does the LCG. It can be inferred that under LCG and PUG lubrication, abrasive wear plays the dominant role and little adhesive wear is exhibited. As-prepared grease with different contents of base oil shows varying consistency, resulting from the different oil-bleeding ability. Therefore, the consistency of grease determines the lubrication conditions. The LCG (80\% MO), LCG (85\% MO), and LCG (80\% PAO) operate under starved lubrication conditions, showing higher wear volume. The PUG and other LCG operate under fully flooded conditions, providing lower wear volume.

The roughness of the worn surface is displayed in Table 2. The roughness of the worn surface under LCG with $80 \mathrm{wt} \%$ and $85 \mathrm{wt} \%$ base oil lubrication shows a larger value than that under LCG with $90 \mathrm{wt} \%$ base oil, further indicating that the LCG with higher concentration of base oil shows better anti-wear ability. The wear tracks lubricated by the PAO-based PUG are rougher than those of the MO-based PUG, and the roughness of wear tracks lubricated by LCG appears with the same regularity, indicating that as-prepared MO grease has better anti-wear ability. It is of great significance for the grease with good physicochemical properties, anti-corrosion, and frictionreducing and anti-wear performance to improve the durability and reliability of mechanical systems.

\subsection{XPS analysis of the worn surface}

To further explore the tribology mechanism of grease lubrication, the elemental composition and chemical state on the worn surfaces were analyzed by XPS. Figure 10 shows the XPS spectra of typical elements on the worn surfaces. The peak of C1s at $284.8 \mathrm{eV}$

Table 3 Roughness of the worn surface lubricated by as-prepared grease (unit: $\mathrm{nm}$ ).

\begin{tabular}{cccc}
\hline \multicolumn{2}{c}{$\begin{array}{c}\text { Grease } \\
\text { roughness }(R a)\end{array}$} & $\begin{array}{c}R a(\text { grease with } \\
\text { MO) }\end{array}$ & $\begin{array}{c}R a \text { (greasse with } \\
\text { PAO) }\end{array}$ \\
\hline \multirow{4}{*}{ LCG } & $80 \mathrm{wt} \%$ & 156.254 & 224.562 \\
& $85 \mathrm{wt} \%$ & 58.861 & 326.287 \\
& $90 \mathrm{wt} \%$ & 37.546 & 89.426 \\
\hline \multirow{2}{*}{ PUG } & $80 \mathrm{wt} \%$ & 49.992 & 89.745 \\
& $85 \mathrm{wt} \%$ & 49.027 & 54.386 \\
& $90 \mathrm{wt} \%$ & 67.186 & 80.769 \\
\hline
\end{tabular}



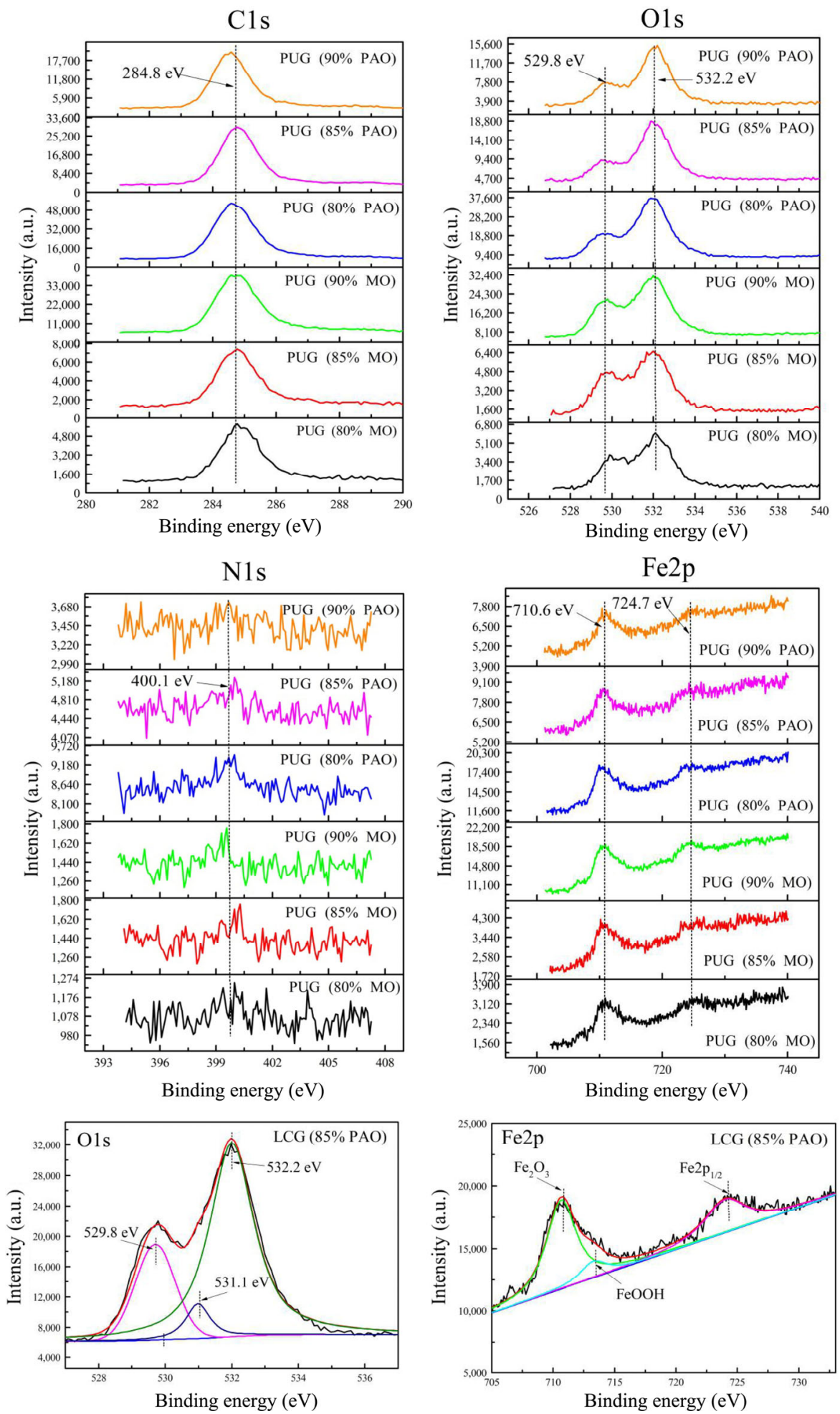

Fig. 10 X-ray photoelectron spectra of the elements on the worn surface lubricated by as-prepared salt-spray resistant greases.

is defined as the carbon in the atmosphere, as the reference. The peaks of $\mathrm{O} 1 \mathrm{~s}$ at 529.9 and $532.2 \mathrm{eV}$ are attributed to the generation of iron oxide [32]. Fe2p spectra exhibit two peaks at 710.6 and $724.7 \mathrm{eV}$, further demonstrating the appearance of $\mathrm{Fe}_{2} \mathrm{O}_{3}$ and $\mathrm{FeO}(\mathrm{OH})$. The peak of N1s at $400 \mathrm{eV}$ indicates the appearance of $\mathrm{C}-\mathrm{N}$ bonding and nitrogen transformation to amine or nitrogen oxide, possibly ascribed to thickener 
components and tribochemical reaction products [33]. XPS analysis can powerfully support the formation of tribochemical reaction film on the worn surfaces. These new products $\left(\mathrm{Fe}_{2} \mathrm{O}_{3}, \mathrm{FeO}(\mathrm{OH})\right.$, nitrides) were formed by the reaction of active elements, such as $\mathrm{Fe}$, $\mathrm{O}$, and $\mathrm{N}$, on the friction interface. The tribochemical reaction film and as-deposited thickener on the worn surface prevent the direct contact of the friction pair. Thus, the tribochemical reaction film and as-deposited thickener as the protective layer contribute to the enhancement of wear resistance and load-carrying capacity [34].

During the process of grease lubrication, the bulk of grease was pushed outside the contact area, promoting grease lubrication at the starved areas. When the residual grease was subjected to the shear and stress of friction pairs, the original structure of the thickener was destroyed and deformed. Thus, the base oil was released from the thickener structure and replenished the contact area [35]. The fluidity of grease determines the bleeding-oil capacity, further determining the lubrication conditions of grease. The base oil and thickener determines the bleeding-oil ability of grease [13]. A higher content of thickener results in grease with poor oil-bleeding ability. Therefore, grease with higher content of thickener operates under starved conditions. Once lacking the base oil, the thickener is deposited on the worn surface, preventing direct contact with the metallic substrate, and the deposited layer acts as a protective film, promoting the formation of tribochemical reaction film. As shown in Figure 8, the lubrication of LCG $(80 \% \mathrm{MO})$, LCG $(85 \% \mathrm{MO})$, and LCG (80\% PAO) belongs to the starved condition. When the grease operates under fully flooded conditions, the oil film and thickener take part in the lubrication process, and the tribochemical reaction occurs on the contact surface, contributing to the enhancement of the lubrication function [36]. As shown in Figs. 8 and 9, the PUG and LCG (90\% MO), LCG (85\% MO), and LCG (90\% MO) are under fully flooded lubrication conditions. In the process of friction, the tribochemical reaction film is continuously ground to form new film, accompanied by a gradually polished and smoothed surface. Thus, the furrows are reduced [37]. The grease could form a physical absorption film or chemical absorption film on the worn surface to provide a low-shear-resistance interface. The synergistic effect of grease film, thickener-deposited film, and tribochemical reaction film plays a dominant role in lubrication function. The PUG containing $90 \%$ MO provides the best lubrication function, further demonstrating the tribological mechanism. The schematic diagram of the synergistic lubrication effect is shown in Fig. 11.

The acceleration effect of corrosion and wear on each other has become an important factor in the failure of mechanical equipment, with the resulting failure and damage to equipment having never been fully resolved. Grease, to some extent, can solve this difficult problem owing to two basic characteristicssealing and lubrication. However, the corrosion resistance of grease has not yet been explored. Considering the multi-phase formulation of grease, each component could play a significant role in regulating performance characteristics.

In terms of the effect of the base oil, thickener, and its composition/structure on the performance of grease, experimental results demonstrate that regulation of

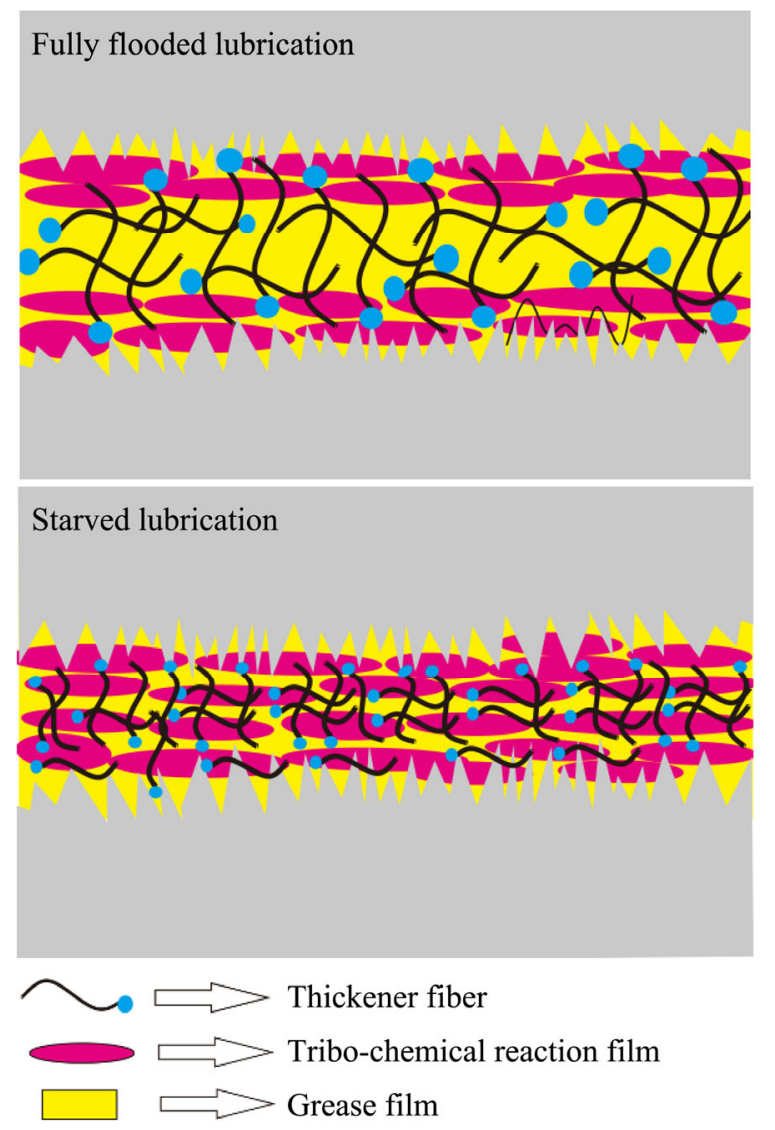

Fig. 11 The schematic diagram of tribological mechanism of as-prepared grease. 
grease formulation can achieve good physicochemical properties, salt-spray resistance, and tribological performance. With the rapid development of modern industrial technology and equipment, regulating grease formulation is of significance in responding to complicated working conditions, especially regarding marine engineering/mechanical equipment.

\section{Conclusions}

Here, various greases were successfully synthesized via regulating base oil (mineral oil, poly- $\alpha$-olefin) and thickener (lithium complex soap and polyurea), with their salt-spray resistant property and tribological performance evaluated in detail. The following conclusions can be drawn:

(1) Regulation of grease formulation obtains highperformance products with high dropping point, colloidal stability, corrosion resistance, and thermal stability. Good physicochemical properties of PUG and LCG with $80 \mathrm{wt} \% \mathrm{MO}$ are mainly attributed to the interaction between the base oil and thickener.

(2) As-prepared greases have superior salt-spray resistance owing to a good sealing effect, thereby preventing the invasion of corrosive media, extending service life, and enhancing operation reliability.

(3) Friction reduction and wear resistance are regulated via grease formulation (friction coefficient at $0.07-0.10$, wear volume reduced by orders of magnitude), especially PUG prepared by $\mathrm{MO}$ with a more pronounced effect.

(4) Although the damage under grease lubrication is mainly caused by abrasive wear, the synergy of grease film, thickener-deposited film, and tribochemical film (composed of $\mathrm{Fe}_{2} \mathrm{O}_{3}, \mathrm{FeO}(\mathrm{OH})$, and nitrogen oxide) contributes to excellent friction-reducing and anti-wear abilities.

\section{Acknowledgements}

The authors gratefully acknowledge the financial support provided by the National Natural Science Foundation of China (No. 51705435), Fundamental Research Funds for the Central Universities (2018GF05), and Key Laboratory of Material Corrosion and Protection of Sichuan (2018CL14).
Open Access This article is licensed under a Creative Commons Attribution 4.0 International License, which permits use, sharing, adaptation, distribution and reproduction in any medium or format, as long as you give appropriate credit to the original author(s) and the source, provide a link to the Creative Commons licence, and indicate if changes were made.

The images or other third party material in this article are included in the article's Creative Commons licence, unless indicated otherwise in a credit line to the material. If material is not included in the article's Creative Commons licence and your intended use is not permitted by statutory regulation or exceeds the permitted use, you will need to obtain permission directly from the copyright holder.

To view a copy of this licence, visit http://creativecommons.org/licenses/by/4.0/.

\section{References}

[1] Arora A K, Jaswal V S, Singh K, Singh R. Applications of metal/mixed metal oxides as photocatalyst: (A review). Orient J Chem 32(4): 2035-2042 (2016)

[2] Chen Q J, Jiang W, Zhang F B, Dong Y H, Zhou X L. Research on salt spray and electrochemical corrosion of FeCo-based bulk amorphous alloys. Rare Metal Mater Eng 45(9): 2322-2326 (2016)

[3] El-Mahdy G A, Nishikata A, Tsuru T. Electrochemical corrosion monitoring of galvanized steel under cyclic wet-dry conditions. Corros Sci 42(1): 183-194 (2000)

[4] Sharma M M, Tomedi J D, Parks J M. A microscopic study on the corrosion fatigue of ultra-fine grained and conventional Al-Mg alloy. Corros Sci 93: 180-190 (2015)

[5] Panchenko Y M, Marshakov A I. Long-term prediction of metal corrosion losses in atmosphere using a power-linear function. Corros Sci 109: 217-229 (2016)

[6] El-Mahdy G A, Kim K B. Monitoring the atmospheric corrosion loss of copper during wet/dry cyclic conditions in oxalic acid solutions. Corrosion 63(2): 171-177 (2007)

[7] Yeong S K, Luckham P F, Tadros T F. Steady flow and viscoelastic properties of lubricating grease containing various thickener concentrations. J Colloid Interface Sci 274(1): 285-293 (2004)

[8] Rezasoltani A, Khonsari M M. On the correlation between mechanical degradation of lubricating grease and entropy. Tribol Lett 56(2): 197-204 (2014)

[9] Chen J G. Synthesis, characterization, and tribological behavior 
of neopentyl polyol ester-based and mixed oil-based titanium complex grease. Tribol Lett 40(1): 149-154 (2010)

[10] Salomonsson L, Stang G, Zhmud B. Oil/thickener interactions and rheology of lubricating greases. Tribol Trans 50(3): 302-309 (2007)

[11] Huang L, Guo D, Liu X, Xie G X, Wan G T Y, Wen S Z. Effects of nano thickener deposited film on the behaviour of starvation and replenishment of lubricating greases. Friction 4(4): 313-323 (2016)

[12] Lugt P. Modern advancements in lubricating grease technology. Tribol Int 97: 467-477 (2016)

[13] Baart P, der Vorst B, Lugt P M, van Ostayen R A J. Oilbleeding model for lubricating grease based on viscous flow through a porous microstructure. Tribol Trans 53(3): 340-348 (2010)

[14] Cen H, Lugt P M, Morales-Espejel G. On the film thickness of grease-lubricated contacts at low speeds. Tribol Trans 57(4): 668-678 (2014)

[15] Delgado M A, Valencia C, Sánchez M C, Franco J M, Gallegos C. Thermorheological behaviour of a lithium lubricating grease. Tribol Lett 23(1): 47-54 (2006)

[16] Lugt P M. A review on grease lubrication in rolling bearings. Tribol Trans 52(4): 470-480 (2009)

[17] De Laurentis N, Cann P, Lugt P M, Kadiric A. The influence of base oil properties on the friction behaviour of lithium greases in rolling/sliding concentrated contacts. Tribol Lett 65(4): 128 (2017)

[18] Mao D H, Feng H, Sun X Y. Preparation of hyperthermal lithium complex grease. Trans Nonferr Metals Soc China 15(6): 1361-1366 (2005)

[19] Skibińska A, Żółty M. Determination of thermal-oxidation stability of lubricating greases. Part 3-Lithium-complex greases. Nafta-Gaz 74(1): 61-66 (2018)

[20] Shu J, Harris K, Munavirov B, Westbroek R, Leckner J, Glavatskih S. Tribology of polypropylene and li-complex greases with ZDDP and MoDTC additives. Tribol Int 118: 189-195 (2018)

[21] Zhao Q, Zhao G Q, Zhang M, Wang X B, Liu W M. Tribological behavior of protic ionic liquids with dodecylamine salts of dialkyldithiocarbamate as additives in lithium complex grease. Tribol Lett 48(2): 133-144 (2012)

[22] Dai X Z, Guo P, Hong D M, Hui J D, Hui Z M, Geng F. The effect of preparation and characterisation of polyurea grease. Mater Res Innov 19(S5): S5-588-S5-591 (2015)

[23] Garshin M V, Porfiryev Y V, Zaychenko V A, Shuvalov S A, Kolybelsky D S, Gushchin P A, Vinokurov V A. Effect of base oil composition on the low-temperature properties of polyurea greases. Pet Chem 57(12): 1177-1181 (2017)
[24] Lyadova A S, Maksimova Y M, Shakhmatova A S, Kirillov V V, Parenago O P. Urea (Polyurea) Greases. Russ J Appl Chem 91(6): 885-894 (2018)

[25] Wang Z Y, Wu W. The tribological properties of the polyurea greases based on oil-miscible phosphonium-based ionic liquids. Lubr Sci 30(1): 16-22 (2018)

[26] Maksimova Y M, Shakhmatova A S, Ilyin S O, Pakhmanova O A, Lyadov A S, Antonov S V, Parenago O P. Rheological and tribological properties of lubricating greases based on esters and polyurea thickeners. Pet Chem 58(12): 1064-1069 (2018)

[27] Liu L, Sun H W. Impact of polyurea structure on grease properties. Lubr Sci 22(9): 405-413 (2010)

[28] Hao G D, Yao Z P, Jiang Z H. Salt spray corrosion test of micro-plasma oxidation ceramic coatings on Ti alloy. Rare Metals 26(6): 560-564 (2007)

[29] Tang Y, Song A M. Effect of salt spray conditions on test results. Microelectronics 39(2): 289-292 (2009)

[30] Xiong C H, Mi H Y, Feng Q, Wu B J. Comparative studies on low noise greases operating under high temperature oxidation conditions. China Pet Process Petrochem Technol 16(4): 100-106 (2014)

[31] Yan J C, Zeng H, Liu T, Mai J H, Ji H B. Tribological performance and surface analysis of a borate calcium as additive in lithium and polyurea greases. Tribol Trans 60(4): 621-628 (2017)

[32] Wu X H, Wang X B, Liu W M. Tribological properties of naphthyl phenyl diphosphates as antiwear additive in polyalkylene glycol and polyurea grease for steel/steel contacts at elevated temperature. $R S C A d v$ 4(12): 6047-6082 (2014)

[33] Wang Z Y, Xia Y Q, Liu Z L, Hu T C. Friction and wear behaviour of laser-textured surfaces under the lubrication of polyurea grease containing various additives. Proc Inst Mech Eng, Part J: J Eng Tribol 225(3): 139-150 (2011)

[34] Singh J, Kumar D, Tandon N. Tribological and vibration studies on newly developed nanocomposite greases under boundary lubrication regime. J Tribol 140(3): 032001 (2018)

[35] Saatchi A, Shiller P J, Eghtesadi S A, Liu T B, Doll G L. A fundamental study of oil release mechanism in soap and non-soap thickened greases. Tribol Int 110: 333-340 (2017)

[36] Paszkowski M, Wróblewski R, Walaszczyk A. Studies of the influence of temperature and the energy state of the surface layer of adsorbents on wall effects in soap-based greases. Tribol Lett 65(1): 19 (2017)

[37] Rawat S S, Harsha A P, Agarwal D P, Kumari S, Khatri O P. Pristine and alkylated $\mathrm{MoS}_{2}$ nanosheets for enhancement of tribological performance of paraffin grease under boundary lubrication regime. J Tribol 141(7): 072102 (2019) 


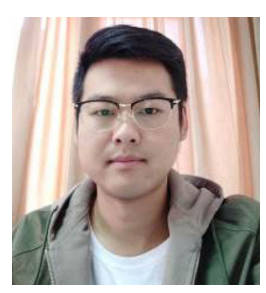

Guanlin REN. He received his bachelor's degree from Shandong Jiaotong University, China, in 2017. He is currently a graduate student

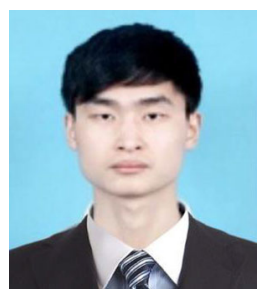

Pengfei ZHANG. He received his bachelor's degree from Zhongyuan University Of Technology, China. He is currently a graduate student

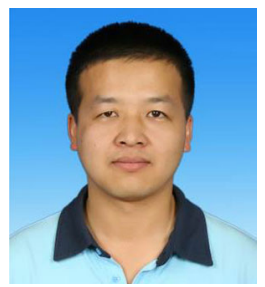

Xiangyuan YE. He is currently an instructor at Baoji University of Arts and Sciences, China. He received his Ph.D. degree from Lanzhou Institute of Chemical

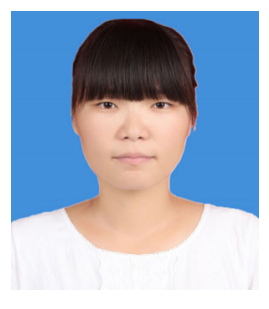

Wen LI. She is currently an associate professor at Southwest Jiaotong University, China. She received her Ph.D. degree from Lanzhou Institute of Chemical Physics, Chinese

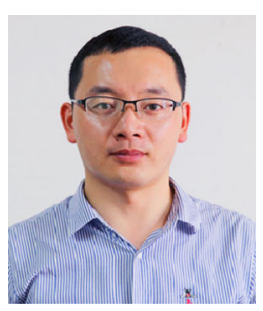

Xiaoqiang FAN. He is currently an associate professor at Southwest Jiaotong University, China. He received his Ph.D. degree from Lanzhou Institute of Chemical Physics, Chinese Academy Science in 2016, China. He received his bachelor's degree in 2011 from Qingdao University

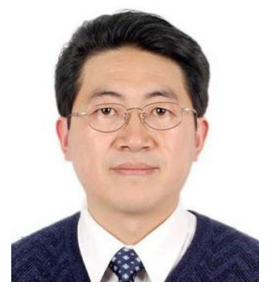

Minhao ZHU. He received his bachelor's degree and master's degree from Southwest Jiaotong University, China, in 1990 and 1993, respectively. He has been working at Southwest Jiaotong University since 1993. From 1996 to 2001, he received his Ph.D. degree from Southwest Jiaotong University, China. $\mathrm{He}$ is a professor, an advisor of Ph.D. students and at School of Mechanical Engineering, Southwest Jiaotong University, China. His research interests include design of lubricating materials and tribological properties of lubricating grease.

at the School of Mechanical Engineering, Southwest Jiaotong University, China. His research interests include design of lubricating materials and tribological properties of lubricating grease.

Physics, Chinese Academy Science in 2016, China. He received his bachelor's degree in 2011 from Northwest Normal University, China. His research interests cover nanomaterials, polymer, and the related tribological properties.

Academy Science in 2017, China. She received her bachelor's degree in 2011 from Liaocheng University, China. Her research interests cover nanoenergy materials, micro-nanodevices, optoelectronic devices, and micro-nanofabrication.

of Science \& Technology, China. His research areas cover lubricating oil/grease, nanomaterials, corrosion, tribology, and surface engineering. He has published over 30 papers in international journals, such as ACS Applied Materials and Interfaces, Nanoscale, Carbon, ACS Sustainable Chemistry \& Engineering, Journal of Colloid Interface Science, Applied Surface Science, Tribology International, and Tribology Letters.

Cheung Kong Scholars, and the Dean of School of Materials Science and Engineering. His research areas cover fretting wear, fretting fatigue, surface engineering, and design of fastener connection. He has published over 200 papers in international journals, such as Carbon, Tribology International, Surface \& Coatings Technology, Tribology Letters, Wear, and Friction, receiving more than 1,000 citations. 